\title{
Hopeful struggling for health - Experiences of participating in computerized cognitive training and aerobic training for persons with stress-related exhaustion disorder
}

Therese Eskilsson ${ }^{1,2^{*}}$, Anncristine Fjellman-Wiklund ${ }^{1}$, Elin Ek Malmer ${ }^{3}$, Anna Stigsdotter Neely ${ }^{4,5}$, Hanna Malmberg Gavelin ${ }^{4,6}$, Lisbeth Slunga Järvholm², Carl-Johan Boraxbekk ${ }^{7,8}$, and Maria Nordin ${ }^{4}$.

${ }^{1}$ Department of Community Medicine and Rehabilitation, Physiotherapy, Umeå University, Umeå, Sweden

${ }^{2}$ Department of Public Health and Clinical Medicine, Sustainable Health and Medicine, Umeå University, Umeå, Sweden

${ }^{3}$ Department of Rehabilitation Medicine, Danderyd Hospital, Stockholm, Sweden

${ }^{4}$ Department of Psychology, Umeå University, Umeå, Sweden

${ }^{5}$ Department of Social and Psychological Studies, Karlstad University, Karlstad, Sweden ${ }^{6}$ Academic Unit for Psychiatry of Old Age, University of Melbourne, Melbourne, Australia

${ }^{7}$ Danish Research Centre for Magnetic Resonance, Centre for Functional and Diagnostic Imaging and Research, Copenhagen University Hospital Hvidovre, Denmark

${ }^{8}$ Department of Radiation sciences, Umeå University, Umeå, Sweden

Corresponding author: Therese Eskilsson, Department of Community Medicine and Rehabilitation, Physiotherapy, Umeå University, SE- 90187 Umeå, Sweden. E-mail: therese.eskilsson@umu.se

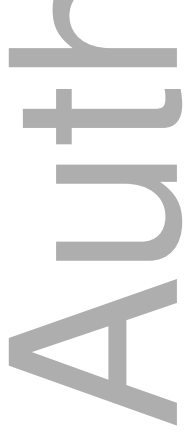

This is the author manuscript accepted for publication and has undergone full peer review but has not been through the copyediting, typesetting, pagination and proofreading process, which may lead to differences between this version and the Version of Record. Please cite this article as doi: $10.1111 /$ sjop. 12623

This article is protected by copyright. All rights reserved 
2 MRS. THERESE ESKILSSON (Orcid ID : 0000-0002-2402-562X)

5 Article type : Empirical Paper

6 Section : Cognition and Neurosciences

9 Number of words excluding abstract: 5728

\section{INTRODUCTION}

11 Stress-related ill-health has increased dramatically in recent years in Sweden, and

12 among these, exhaustion disorder (ED) is a common cause of sick leave (Swedish

13 Social Insurance Agency, 2017). ED (F43.8A, ICD-10-SE) (National Board of

14 Health and Welfare, 2003) is a criteria-based diagnosis and used in Swedish clinical

15 practice as a clinical manifestation of burnout (Grossi, Perski, Osika, \& Savic, 2015;

16 Wallensten, Asberg, Wiklander, \& Nager, 2019). ED is characterized by

17 psychological and physical exhaustion as a consequence of identified stressors

18 (work- or non-work-related), present for at least six months (National Board of

19 Health and Welfare, 2003). Different symptoms are also included in the diagnostic

20 criteria, and one of the most prominent symptoms is cognitive impairments (Grossi

21 et al., 2015).

22 Rehabilitation for persons with ED and clinical burnout has usually included

23 cognitive behavioural interventions or multimodal interventions, but with no effect

24 on symptoms or return to work compared with control groups (Grossi et al., 2015;

25 Wallensten et al., 2019). The recovery time may be long with remaining symptoms

26 and reduced work ability (Malmberg Gavelin et al., 2018; Stenlund, Nordin, \&

27 Slunga Järvholm, 2012) and symptoms of exhaustion are persistent (Glise, Ahlborg

28 Jr, \& Jonsdottir, 2012). Cognitive impairments have also been shown to be long-

29 lasting despite treatment with cognitive behavioural therapy (CBT) (Eskildsen,

30 Andersen, Pedersen, \& Andersen, 2016; Jonsdottir et al., 2017) and work related

31 activities (Oosterholt, Maes, Van der Linden, Verbraak, \& Kompier, 2016;

32 Österberg, Skogsliden, \& Karlsson, 2014). The most common cognitive impairments 
33 are reported in executive functions, attention, episodic and working memory (Grossi

34 et al., 2015; Malmberg Gavelin, Boraxbekk, Stenlund, Slunga Järvholm, \&

35 Stigsdotter Neely, 2015). In addition, people with stress-related exhaustion

36 experience that their cognitive abilities in everyday life are impaired for a long

37 period of time (Eskildsen et al., 2016; Oosterholt et al., 2016).

38 We have recently evaluated two different interventions specifically directed to

39 improving cognitive functioning in addition to a multimodal rehabilitation

40 programme (MMR) for persons with ED. A 12-week intervention with computerized

41 cognitive training improved performance on the executive function updating and

42 episodic memory (Malmberg Gavelin et al., 2015) whereas aerobic training at a

43 moderate-vigorous intensity during 12 weeks improved performance in episodic

44 memory (Eskilsson, Slunga Järvholm, Malmberg Gavelin, Stigsdotter Neely, \&

45 Boraxbekk, 2017). The computerized cognitive training also demonstrated cognitive

46 improvements at long-term follow-up (Malmberg Gavelin et al., 2018).

47 However, in order to implement cognitive and aerobic training in rehabilitation, it is

48 important to understand how people with ED perceive these interventions. Thus, the

49 overall aim of this study was to explore experiences from persons with ED after

50 participating in a 12 -week intervention of either computerized cognitive training or

51 aerobic training. . Specific aims were to investigate what was perceived to be

52 advantages/disadvantages of the intervention and if there were any

53 facilitators/barriers to achieve the goal of the training. METHODS

\section{$54 \quad$ Participants and study design}

55 The current study is part of the Rehabilitation for Improved Cognition (RECO) -

56 study, which was a randomized controlled trial, conducted at the Stress

57 Rehabilitation Clinic at the University Hospital in Umeå, Sweden. The overall aim of 58 the RECO-study was to investigate whether the addition of a 12-week period of

59 computerized cognitive training or aerobic training could further enhance cognitive

60 function in patients with ED participating in an MMR program. The RECO-study

61 has previously been described in detail (Eskilsson et al., 2017; Malmberg Gavelin et

62 al., 2015). Inclusion criteria in the study were: confirmed ED according to criteria

63 established by the Swedish National Board of Health and Welfare, 18-60 years of 
64 age, currently employed, considered by physician and psychologist as suitable for

65 MMR in group, no need of other treatment or rehabilitation, no known abuse of

66 alcohol or drugs and no participation in other intervention studies. Twenty-three

67 eligible patients with ED that most recently completed the RCT study and the

68 interventions were asked to participate in individual interviews. We used purposive

69 sampling to provide a variation in age, education, occupation, and representing

70 participants from the computerized cognitive training and aerobic training

71 interventions as well as dropouts. Ten persons declined to participate where the most

72 common cause was lack of time due to work rehabilitation. In total 13 remaining

73 persons ( 11 women and two men) accepted, gave informed consent and were

74 interviewed. The characteristics of the participants were; $30-56$ years of age; 11 with

75 university education; 10 married or cohabiting, and 10 worked with people (for

76 example nurse, teacher) and three with data (for example secretary, computer

77 operator) (Kohn \& Schooler, 1983). Moreover, five participants were on full-time

78 sick leave, and eight were on part-time sick leave before the intervention. After the

79 intervention four participants were on full-time sick leave including vocational

80 training, five were on part-time sick leave and four participants reported no sick-

81 leave.

82 The individual interviews were analyzed with Qualitative Content Analysis (QCA)

83 (Graneheim, Lindgren, \& Lundman, 2017; Graneheim \& Lundman, 2004). QCA is a

84 useful systematic method of analyzing written or verbal communication, often used

85 in analyses of experiences and reflections of people (Downe-Wamboldt, 1992; Hsieh

86 \& Shannon, 2005). QCA focuses on differences between and similarities within

87 codes and categories. The method allows both manifest and latent interpretations of

88 the content, but the interpretations vary in depth and level of abstraction (Graneheim

89 et al., 2017; Graneheim \& Lundman, 2004).

\section{Context}

91 The participants took part in a 24-week MMR programme, consisting of group-based

92 CBT, individual physical activity on prescription, and vocational measures. Each

93 CBT group consisted of eight participants who met once a week in 22 three-hour

94 sessions. The purpose of the group sessions was to change the participants'

95 behaviour patterns in order to promote better health, function and work capacity. 
96 Therefore, two individual meetings were performed to set individual targets for

97 behavioural change. Each CBT group-session started with relaxation, followed by

98 specific themes: stress and recovery; sleep; and coping with emotions.

\section{Intervention}

100 After 12 weeks of MMR, a randomization by CBT group was conducted to either

101 continue MMR with an addition of computerized cognitive training or continued

102 MMR with an addition of aerobic training. The additional training was performed

103 three times per week for 12 weeks. The computerized cognitive training was

104 performed at home by a web-based program and lasted approximately 15-20 minutes

105 per session. The aerobic training was performed as group indoor cycling

106 ("spinning"), at a training center conveniently located for the participant. Each

107 training session was 40 minutes long, and the participants' exercised at a moderate to

108 vigorous intensity. These additional training programs have previously been

109 described in detail (Eskilsson et al., 2017; Malmberg Gavelin et al., 2015).

\section{Data collection}

111 The interviews were conducted after completion of the MMR programme and the

112 additional training programmes. Interview data were collected from five participants

113 from the computerized cognitive training programme, and five participants from the

114 aerobic training programme. Moreover, three drop outs; one from the cognitive

115 training and two from the aerobic training were interviewed (Figure 1).

[Insert Figure 1 about here]

117 Written and verbal information about the study were given to all participants, along

118 with a written informed consent. The study was approved by the Regional Ethical

119 Review Board in Umeå, Sweden (Approval No. 2012-357-32, 2010-53-31). All

120 interviews were performed at the Stress Rehabilitation Clinic at the University

121 Hospital in Umeå, Sweden, where the MMR programme was conducted. A

122 physiotherapist (TE) and a social scientist interviewed the participants. The

123 interviewers had never met the participants before the interviews. The interviews

124 were performed with the help of an interview guide with semi-structured questions

125 regarding participating in respective intervention; computerized cognitive training or 
126 aerobic training. Example of questions for this paper was: Please tell me about

127 barriers/facilitators to achieve the goal of the training, What have you done in order

128 to overcome the barriers? Did you experience advantages/disadvantages with the

129 training? If yes, which? What made you succeed/not succeed in your training? Minor

130 adjustments were made to the questions between interviews so that information

131 provided in one interview could be taken into consideration in a subsequent

132 interview. The interviews lasted between 20-60 minutes and were audio-recorded

133 and transcribed verbatim by a professional transcriber.

\section{Data analysis}

135 The interviews were analyzed using QCA according to Graneheim \& Lundman

136 (Graneheim et al., 2017; Graneheim \& Lundman, 2004). Each transcript was read

137 repeatedly as a whole and in parts during the data analysis. The text was divided into

138 meaning units and sentences, and phrases relevant to the qualitative aim of the study

139 were identified and sorted into condensed meaning units and labelled with codes. To

140 find similarities and differences, the codes were compared and interpreted

141 repeatedly. Codes, sub-categories and categories were analyzed on a manifest level

142 (close to the text), while the overarching theme included interpretations that

143 corresponded to the meaning of the material.

144 Each interview was read and coded by four researchers in the research group (AFW,

145 EEM, MN, TE). Three were not involved in the RCT study (AFW, EEM, MN) and

146 one was the project coordinator (TE). AFW, EEM and TE are physiotherapists and

$147 \mathrm{MN}$ is a behavioural scientist. AFW, MN and TE have experience from research in

148 stress-related health, qualitative studies, occupational health and rehabilitation and

149 teaching in stress-related health.

150 During all steps of the analysis each of the researchers mentioned above,

151 independently made the coding, followed by a mutual comparison of the result and a

152 final negotiated outcome. The results were also presented and discussed, in a peer

153 debriefing (Lincoln \& Guba, 1985), with staff at the Stress Rehabilitation Clinic. The

154 staff recognised the results as consistent with what they perceived that the

155 participants expressed. The results are presented with quotes from the interviews,

156 sub-categories, categories and a theme. 


\section{RESULTS}

\section{Hopeful struggling for health - the theme}

159 The theme hopeful struggling for health reflects the participants' struggle with

160 changing from who they were to who they wanted to become and as a participant

161 mentioned "it was an interesting before and after experience". Despite the struggle,

162 the participants express hope and wishes for a healthy and sound future. Recovery

163 from ED requires hard work, but "the longer they worked in the programme the

164 better they became". The theme constitutes three categories, support, motivation and

165 sensations since the participants reported these to be the most important parts for

166 keeping on struggling and for success.

167 Despite being asked to reflect on participating in computerized cognitive training or

168 aerobic training, the participants' interviews entail to a large extent, experiences

169 from recovering from ED and participating in the MMR programme. However, the

170 results indicate that experiences of participating in computerized cognitive training

171 or aerobic training contributed to a hopeful struggle for health.

[Insert Table 1 about here]

\section{Support}

174 Support served as a basis for the whole recovery process and the category support

175 contained three sub-categories: assistance from others, technological support, and

176 planning and routine.

177 Assistance from others

178 To be loved and accepted, despite not functioning as before was essential for the 179 recovery process. position the saddle and be there as a support when everything was new" (Participant 11) 
"My family has been very involved in this (process) and they have taken part in my computer exercises and we have discussed it" (Participant 5)

185 Family and close relatives were a concrete support for the participants during the 186 training.The meetings in the MMR programme were highly appreciated. In fact, 187 these meetings were what encouraged the participants the most and gave them hope 188 that their persistence would lead them to recovery one day. .../ to meet the group, to meet peers in the same situation and get tips and

190 ideas and even support... That's what's made me stronger" (Participant 5)

191 The recognition from others with the same diagnosis contributed to larger insights

192 about ED, which was reported as a relief, and the feeling of not being alone was 193 accentuated.

194 The participants reported that they had wished that the computerized cognitive 195 training and aerobic training had been better adapted to their situation, and for 196 instance being performed together with the MMR group.

"What if we had gone (aerobic training) the whole group ... and had classes together .... A little bit more adapted /.../ a little calmer ... a bit lower music ... and with the support of the others" (Participant 11)

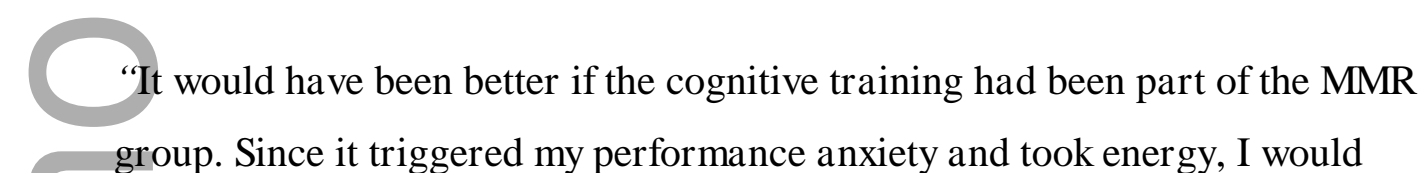
group. Since it triggered my performance anxiety and took energy, I would

02 have needed support in this" (Participant 6)

203 In summary, to be able to conduct the exercises included in the computerized 204 cognitive training or aerobic training, support from the family and from others in the 205 same situation was crucial.

206 Technological support

207 Technological support was an important factor to manage the exercises. In the 208 aerobic training, some participants had previously over-trained. 
"The pulse watch was great, then I knew that, aha - this is enough! And also, it was so much fun! (Participant 11)

211 The pulse watch was an appreciated tool to keep them from overdoing the exercises

212 and to help them listen and learn bodily signals. The pulse watch was also a support

213 in limiting themselves not being enticed to increase the workout by other stimuli

214 such as music or pepping from the session leader. At the same time, it felt unfamiliar

215 to adapt the training to a lower intensity. Some described that they had continued to

216 use the pulse watch in their training after the intervention had ended.

217 The technology was essential for the computerized memory training. When it failed,

218 the training could not be completed with frustration as a consequent reaction. In one

219 case, failing of the participant's own Internet connection, was the reason for drop-

220 out.

221 “... also, my Internet connection failed and I was thrown out all the time.

222 /.../ That was an additional stressor and sometimes I had to do the tasks three

223 times before they got registered. This became very hard and in the end, I

224 didn't manage. / ... / I fell behind and it became a burden, so I decided to

225 drop out" (Participant 1)

226 For other participants in the computerized cognitive training, the technology was

227 perceived as smooth and without problem.

228 Planning and routine

229 Planning and development of routines in the training were important sources of

230 support. Permission to exercise during working hours, distributing the training over

231 several days, or dividing it into smaller parts, facilitated the computerized cognitive

232 training.

233 "So I have to divide it (the cognitive training) up in chunks and take micro

234 pauses all the time. Even if I think it feels okey, I have to take these micro

235 pauses as a preventive measure” (Participant 5)

This article is protected by copyright. All rights reserved 
236 Some participants showed awareness of their own needs and stopped the training,

237 even if it felt they could go on, to save energy for the rest of the day or week.

"It (cognitive training) took a lot of energy from the day, about a fourth of - my energy. When I got a routine for the practice, it took much less energy” (Participant 6)

241 For some participants it was difficult to get started with aerobic training, but when it

242 became mandatory by participating in the project with a clear framework, the

243 participants enjoyed it. However, lack of exercise groups that suited the participant's

244 schedule, or living in areas far from training centres, were obstacles to creating

245 lasting routines of aerobic training.

$246 \quad$ “... and every other week, when I have had the kids, I thought I can exercise

247 during lunch hour, but there (at the gym) weren't that many lunch training

248 sessions and then it became difficult to make it happen" (Participant 12)

249 To conclude, it was important to plan and create routines for the cognitive training so

250 that it did not consume too much of the available energy. Clear routines provided

251 support also for conducting the aerobic training, however, they became more

252 difficult to uphold if the accessibility to training was limited.

\section{Motivation}

254 Motivation was an important part for conducting both the computerized cognitive

255 training and the aerobic training. The category motivation comprised of three sub-

256 categories: balance and timing, feedback and pleasure.

257 Balance and timing

258 Balancing and timing of activity, i.e. matching the extra activities to the

259 rehabilitation process and work- and family life, were discussed among all

260 participants. The participants expressed it to be hard to make ends meet combining

261 the MMR programme, the extra exercises that the aerobic and cognitive conditions

262 required, work, family and life itself. Both the computerized cognitive training and 
263 aerobic training were thus put aside to prioritize children, family or work during the

264 intervention. "/.../ twice a week would have been enough for me. /.../ It can feel like a failure when you don't succeed in working out three times a week as

proposed" (Participant 10)

$268 \quad$ "...there must also be time for it (the computer training). You have more

269 working hours and there is no time to sit down and (do the training) no

270 energy ... you consume so much energy at work” (Participant 5)

271 However, it was possible to prioritize both training and the family when work was in 272 balance. The participants also prioritized themselves more after having gone through 273 the MMR programme and the additional interventions.

274 The motivation was declining when the participants had to struggle with managing 275 their own performance anxiety.

“... it was a performance thing ... it was hard to do it (the cognitive training) because you wanted to perform better than last time and at the same time it was harder since you levelled up” (Participant 6)

279 This was especially true for the computerized cognitive training, where the exercises 280 increased in difficulty when the participants passed a certain level.

281 Feedback

282 Objective feedback from heart rate curves in the aerobic training and measures of 283 physical fitness level from professionals was appreciated. This, in combination with

284 getting support from the physiotherapist in customizing the aerobic training provided 285 a sense of security. “... I exercised too much ... so the exercise became less frequent (when entering the intervention), but controlled ... and that was valuable. I needed someone who steered me in all aspects of reality" (Participant 2) 
289 Customized training consisted of both graded activity and learning to set boundaries.

290 Participants in the computerized cognitive training wished for feedback on measures 291 of cognitive function.

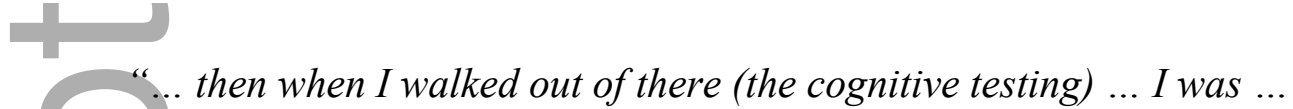

293 personally I was really sad /.../ Because it was like a proof that ... how far it

294 had gone /.../I mean, how shall I be able to function ...to do a job?”

295 (Participant 9)

296 Not receiving feedback on measures of cognitive function meant that participants

297 were left with concerns about not being restored again. They also wished for

298 feedback on results from the cognitive training.

299 ...these computer exercises...well, ok there is no feed-back from the

300 (computer) programme" (Participant 4)

301 Because the cognitive training was adaptive and always challenging, there was a

302 great need to get feedback on the training results.

303 Pleasure

304 Joy was an important factor. The participants reported it to be difficult to get started

305 with the aerobic training, but those who went on perceived the exercise to be

306 enjoyable as confidence increased to cope with it. Training in a group, to music at

307 their own pace worked well.

308 “... The group leader was positive and the music was pepping. I thought it

309 was great fun /.../You feel good... you become happier... you become calmer somehow" (Participant 9)

311 However, some participants could feel that the music was too loud and would have

312 preferred to exercise in a calmer environment.

313 On the contrary, the computerized cognitive training was initially very fun and

314 inspirational but turned out to become more stressful and therefore difficult to

315 prompt at the end of the intervention. In fact, the cognitive training ended up as 
316 being perceived as boring and the participants expressed a wish to renew the training

317 program to make it more fun.

318 Honestly, I was bored with the practices at the end. I have tested other types

319 of memory exercises on the Internet and they are much more varied and more

320 fun. Almost like playing a game even though you practice memory.

321 (Participant 4)

322 Thus, pleasure was an important part of motivating oneself to training, where

323 environment, group leaders and music were some important motivators. Cognitive

324 training could be improved and made more fun with more game-like elements.

\section{Sensations}

326 Participants from both the computerized cognitive training and aerobic training

327 reported various sensations. These were mostly positive, at least in retrospect, and

328 included a sense of improved and sustained memory, clearer head, energy, better

329 self-efficacy, increased self-esteem and better understanding of themselves. These

330 were sub-categorised into memory, strength and faith.

Memory

332 The participants experienced that their memory gradually improved.

333 "It (the computer training) gave some effect. I had more acuity, I got better

334 structure at work, I could structure the job a little better... better structure of

335 things, ... it did not get messy when I was to perform certain tasks, easier to

336 keep up with and be able to hold discussions in conversation, find words a

337 little better” (Participant 4)

338 The improved memory increased the participants' ability to work and facilitated

339 conversations.

340 For some it was difficult to single out what had been the most active ingredient in

341 the rehabilitation in improvement of memory.

342 "If it (cognitive improvement) was due to only memory training or if it was

343 due to giving it time to heal, I don't know" (Participant 5) 
344 Time itself could be part of the improvement but also the specific training. It was

345 also clear to some of the participants that the improved memory was noticeable in 346 daily life.

347 "And that's (the aerobic training) what makes this spring so fantastic. When

$348 \quad$ I wake up and feel fresh and don't have to go back to sleep and can

349 remember six numbers in a row!" (Participant 2)

350 The memory gradually improved during the rehabilitation, which facilitated work 351 and everyday life. Strength

352 Participants in the aerobic training expressed that they became stronger mentally and 353 physically which was felt in different situations in everyday life. Aerobic training 354 was exhausting but gave a lot of vigour afterwards.

355 "...of course I was tired from the exercise, but it was a refreshing tiredness

356 ... that gave energy and power" (Participant 10)

357 The participants expressed that the aerobic training gave them a possibility to relax 358 the thoughts since these stopped for a while. It was described as "if the oxygen went 359 to the head" and as "a pause for the brain and exertion for the body instead". This in 360 turn contributed to a better ability to concentrate and remember.

361 Participants who were working, reported that the cognitive training led to fatigue as 362 it consumed all their energy on the training days. my brain hurt for a couple of days (after training) ... I was completely 364 beaten. That's why it was so hard to find that strength ... to get the thoughts

366 Obviously, the participants in the computerized cognitive training needed to have 367 enough energy to perform the cognitive training. However, they were strengthened 368 when they succeeded in the exercises.

"It is mostly my memory I notice... of course your self-confidence is better when you succeed in certain exercises, you feel strengthened." (Participant 5)

This article is protected by copyright. All rights reserved 
372 In summary, aerobic training provided energy after the training sessions, while

373 cognitive training gave some of the participants a feeling of fatigue. The cognitive

374 training was facilitated if there was a balance between activity and recovery in daily

375 life.

$376 \quad$ Faith

377 Faith was strengthened when participants felt they were able to complete the

378 training. In the computer training group participants were hopeful through the

379 computer exercises, despite ups and downs.

380 'Of course I think I got help from this (computer training), I do not doubt it

381 for a second. In the beginning, then the curve pointed upwards very quickly.

382 But then ...there was like a deep dip and then after that it became heavier but

383 of course I think I was helped by it” (Participant 4)

384 One participant in the aerobic training felt that the most valuable part was to

385 complete the intervention, which she had not thought possible.

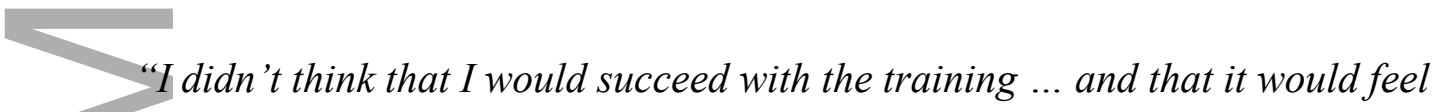

387 so positive. Now I have discovered that I can do aerobic exercise if I do it the right way" (Participant 8)

389 The belief in being physically active meant that some dared to resume previous

390 activities that they had stopped doing since they became ill in ED.

391 To sum, faith was strengthened in both groups and gave them hope for a healty

392 future in work and private life.

394 DISCUSSION

395 The aim of this study was to explore experiences from persons with ED when

396 participating in a 12-week intervention of either computerized cognitive training or

397 aerobic training that was included in an MMR programme. The main findings 
398 showed that it was hard work recovering from ED and the participants struggled with

399 the exercises from the intervention. However, they gradually experienced that the

400 interventions gave confidence and hope for a healthier future. Support - both

401 emotional and instrumental - was described as an important facilitator of the

402 recovery process, including assistance from others, as well as support from

403 technological aids and through finding an appropriate training routine. Motivation

404 was also expressed as a key factor for conducting the training; specifically, the

405 importance of adequate timing, feedback on training progression and training

406 enjoyment were highlighted by the participants as drivers of training motivation.. In

407 addition, both cognitive and aerobic training were perceived as beneficial for

408 improving memory and feeling stronger mentally and physically, leading to

409 increased self-confidence.

410 To recover and regain energy, basic needs may have to be replenished. Relatedness,

411 competence, and autonomy are basic psychological needs emphasized in the self-

412 determination theory (SDT) (Ryan \& Deci, 2000). SDT speaks about how external

413 and internal motivation impact for instance self-regulation. In the present study, it

414 became evident that the pulse watch served as an external motivator for some

415 individuals to start regulating their behaviours. Further, the pulse watch became a

416 tangible tool to learn how to listen to bodily signals and set boundaries for

417 themselves in order to promote health in the recovery process. Setting boundaries to

418 keep balance is key in maintaining a good health (Beckie, 2012). When learning how

419 different pulse levels, i.e. how different activity levels, were perceived bodily the

420 participants could gear themselves towards a healthier activity level. For some,

421 aerobic training was also an intrinsic motivation with feelings of enjoyment.

422 In this study, feedback from the pulse watch and from professionals were important

423 for motivation. Professional competence and support to work with goal-setting and

424 action plans are examples of tools used to facilitate behavioural change (Abraham \&

425 Michie, 2008) which have also been found to be important for persons with long-

426 lasting pain (Andersen, Kohberg, Herborg, Sogaard, \& Roessler, 2014).

427 Additionally, a recent study on home-based cognitive training in long-lasting pain

428 described weekly contact between trial personnel and participants as vital for

429 maintaining training engagement (Baker et al., 2018). In our study, participants in the 
430 computerized cognitive training reported that the training sometimes was boring and 431 that the lack of feedback made the participants' motivation to easily fade. Thus,

432 making training more engaging, e.g., though including game-like elements (Anguera

433 \& Gazzaley, 2015), as well as incorporating more clinician contact could be of value 434 for motivation.

435 According to SDT, fulfilling relatedness, competence and autonomy needs, such 436 external motivation can convert into internal motivation that reflects conducting 437 behaviours due to conviction rather than external pressure. It can be assumed that the 438 need for relatedness can be satisfied by the confirmation of meeting others with the 439 same experiences. In line with this, there was a strong wish from the participants that 440 the computerized cognitive training and aerobic training had been performed

441 together with the MMR group. Research has shown that persons with ED (Eriksson, 442 Karlström, Jonsson, \& Tham, 2010; Fjellman-Wiklund, Stenlund, Steinholtz, \& 443 Ahlgren, 2010) and sick-listed with long-lasting pain (Andersen et al., 2014) who 444 participate in a group-based rehabilitation programme tell about the importance of 445 good encounters with people who understand what they are going through, of being 446 confirmed and of cohesion in the group. This was confirmed by the participants in 447 the present study, but in referral to the MMR group meetings. Cognitive and aerobic 448 training also increased the participants' experience of competence in coping with 449 their situation. However, in our previous study (Malmberg Gavelin et al., 2018), we 450 observed that participants from aerobic training did not maintain their maximal 451 oxygen uptake at one-year follow-up, which indicate that they may have stopped 452 training, suggesting that the concept of autonomy was not reached. Potentially, there 453 may be a need for enhanced intrinsic motivation practice to achieve autonomy for 454 sustained exercise behaviours over time (Teixeira, Carraça, Markland, Silva, \& 455 Ryan, 2012).

456 Support from different sources played an important role in the recovery process.

457 Family support was a basis for successful participation in the intervention. The 458 family is considered to be a universal buffer against stress (Cutrona \& Russel, 1990). 459 It can provide support by emotional and confirmatory support, that can ease stress 460 regardless of stressor (Cutrona \& Russel, 1990). Support from the family may thus 
461 be something to reflect carefully on and work with when developing interventions

462 for persons with ED.

463 After having completed the intervention, the participants perceived that their

464 cognitive functioning had improved which corroborates the results of the cognitive

465 test battery in our previous studies (Eskilsson et al., 2017; Malmberg Gavelin et al.,

466 2015). It was, however, difficult for the participants to specify whether the perceived

467 improvement in memory was due to training or the time for healing. Notably, the

468 participants expressed that the computerized cognitive training and the aerobic

469 training had been beneficial for memory in everyday situations.

470 The recoyery process of cognitive function may further be aggravated by fatigue

471 which is a major symptom in ED. Even if the persons are able to perform

472 complicated tasks, more resources and energy are allocated for the process (Krabbe,

473 Ellbin, Nilsson, Jonsdottir, \& Samuelsson, 2017; Malmberg Gavelin et al., 2017;

474 Oosterholt, Maes, Van der Linden, Verbraak, \& Kompier, 2014; van Dam, Keijsers,

475 Eling, \& Beckers, 2011) than in healthy persons (Krabbe et al., 2017; Oosterholt et

476 al., 2014; van Dam et al., 2011). This excess in energy expenditure may tax on

477 everyday functioning. Participants in the computerized cognitive training described

478 that they needed to have enough energy to perform the cognitive training. Carrying

479 out the aerobic training also took energy, three training sessions per week were

480 difficult to maintain for most of the participants. If interventions such as these are

481 included in treatment, it is important to consider a balance between activity and

482 recovery, and those who are working may require extra attention in balancing the

483 resources and demands. This could be facilitated if planning and clear routines

484 existed for how the training should be organized. The participants also needed

485 appropriate technological support, which for some was a problem during the

486 computerized cognitive training. This is especially important to take into account as

487 persons with ED have impaired cognitive functioning, specifically in domains of

488 relevance for efficient planning and problem solving (Ellbin, Engen, Jonsdottir, \&

489 Nordlund, 2017; Eskildsen, Andersen, Pedersen, Vandborg, \& Andersen, 2015;

490 Jonsdottir et al., 2013; Öhman, Nordin, Bergdahl, Slunga Birgander, \& Stigsdotter

491 Neely, 2007).

This article is protected by copyright. All rights reserved 
492 Contrary to the computerized cognitive training, participants from the aerobic

493 training perceived that they gained energy following the physical activity training

494 sessions. They experienced, that the brain and the mind rested and that the body

495 worked instead. This is in line with our earlier results (Eskilsson et al., 2017) where

496 there was a tendency for a larger improvement in heart rate recovery for participants

497 who improved most in episodic memory. This indicates that aerobic exercise is

498 related to regulation of the autonomic nervous system and an increased

499 parasympathetic reactivation after exercise.

500 Methodological considerations

501 In order to increase trustworthiness triangulation between researchers (Lincoln \& 502 Guba, 1985) was used. Different research fields such as physiotherapy, cognitive-,

503 social- and health psychology as well as stress rehabilitation were represented when

504 conducting the study.

505 For the interviews, we aimed for a variety of participants from both intervention 506 groups (computerized cognitive training and aerobic training) along with dropouts 507 from both groups. The perceptions from the dropouts were regarded as important 508 information to understand how future interventions should be developed. This study 509 was part of a randomized controlled study evaluating both cognitive training and 510 aerobic training which may have made the analyses more demanding. However, the 511 strength of this design is that our results may be applicable in a clinical setting in 512 treatment of ED. More women participated in both this qualitative study as well as in 513 the MMR-programme. For future qualitative studies, more men need to be included 514 as informants to explore if men and women benefit from the same type of treatment 515 of ED.

516 The participants in this study represent the group of persons diagnosed with ED well 517 since they were middle-aged, well-educated, have families, work with people and 518 most of them are women. Thus, the transferability of our results may be made to 519 similar settings.

520 The strengths of our study are the rich and varied interviews and that researchers 521 from different research fields participated in the analyses and interpretations. This 
522 ensured that several interpretations were discussed and negotiated before reaching a

523 final result which helps guarding against over-interpretation of the results and

524 improving trustworthiness. Thus, trustworthiness was ensured through accuracy in

525 the research design, data collection and analysis. The researchers responsible for the

526 intervention study did not participate in the analysis and interpretation of the

527 interviews. However, they were included in discussions of the results and the model,

528 and a negotiated outcome in the research group was reached after minor adjustments.

\section{CONCLUSIONS}

530 It seems to be advantageous in rehabilitation and recovery from ED to include

531 support from various sources such as group support from others who are in the same

532 situation and from family members. Both aerobic and cognitive training were

533 perceived as beneficial for improving memory and feeling stronger both mentally

534 and physically. However, it is important to adjust the aerobic training to fit the

535 patient group by adjusting frequency and, in cases of patients who over-train, to

536 modify intensity. Moreover, the use of a pulse watch may strengthen the practice of

537 setting boundaries. The computerized cognitive training may be ameliorated by

538 including regular feedback and making the exercises more motivating. In addition,

539 the timing and amount of activities in the rehabilitation for persons with ED should

540 be considered.

\section{REFERENCES}

542 Abraham, C., \& Michie, S. (2008). A taxonomy of behavior change techniques used

543 in interventions. Health Psychology, 27(3), 379-387. doi:10.1037/0278-

$544 \quad 6133.27 .3 .379$

545 Andersen, L. N., Kohberg, M., Herborg, L. G., Sogaard, K., \& Roessler, K. K.

546 (2014). "Here we're all in the same boat"- a qualitative study of group based

547 rehabilitation for sick-listed citizens with chronic pain. Scandinavian Journal

548 of Psychology, 55(4), 333-342. doi:10.1111/sjop.12121

549 Anguera, J., \& Gazzaley, A. (2015). Video games, cognitive exercises, and the

550 enhancement of cognitive abilities. Current Opinion in Behavioral Sciences,

$551 \quad$ 4, 160-165. doi:10.1016/j.cobeha.2015.06.002 
552 Baker, K., Georgiou-Karistianis, N., Lampit, A., Valenzuela, M., Gibson, S., \& Giummarra, M. (2018). Computerised training improves cognitive performance in chronic pain: a participant-blinded randomised activecontrolled trial with remote supervision. Pain, 159(4), 644-655. doi:

\subsection{7/j.pain.0000000000001150}

Beckie, T. M. (2012). A systematic review of allostatic load, health, and health disparities Biological Research for Nursing, 14, 311-346. doi:

10.1177/1099800412455688

Cutrona, C. E., \& Russel, D. W. (1990). Type of social support and specific stress: Toward a theory of optimal matching. In Sarason, B. R., Sarason, I. G., \& Pierce, G. R. Wiley series on personality processes. Social support: An interactional view (pp. 319-366). Oxford: John Wiley \& Sons.

Downe-Wamboldt, B. (1992). Content analysis: method, applications, and issues.

Health Care for Women International, 13(3), 313-321. doi:

10.1080/07399339209516006

Ellbin, S., Engen, N., Jonsdottir, I., \& Nordlund, A. (2017). Assessment of cognitive function in patients with stress-related exhaustion using the Cognitive Assessment Battery (CAB). Journal of Clinical and Experimental Neuropsychology, 1-9. doi:10.1080/13803395.2017.1388359

Eriksson, T., Karlström, E., Jonsson, H., \& Tham, K. (2010). An exploratory study of the rehabilitation process of people with stress-related disorders. Scandinavian Journal of Occupational Therapy, 17, 29-39. doi:

\section{$10.1080 / 11038120902956878$}

Eskildsen, A., Andersen, L., Pedersen, A., \& Andersen, J. (2016). Cognitive impairments in former patients with work-related stress complaints - one year later. Stress, 19, 559-566. doi: 10.1080/10253890.2016.1222370

Eskildsen, A., Andersen, L., Pedersen, A., Vandborg, S., \& Andersen, J. (2015).

Work-related stress is associated with impaired neuropsychological test performance: a clinical cross-sectional study. Stress, 18(2), 198-207. doi: $10.3109 / 10253890.2015 .1004629$

Eskilsson, T., Slunga Järvholm, L., Malmberg Gavelin, H., Stigsdotter Neely, A., \& Boraxbekk, C. J. (2017). Aerobic training for improved memory in patients with stress-related exhaustion: a randomized controlled trial. BMC Psychiatry, 17, 322. doi: 10.1186/s12888-017-1457-1 
Fjellman-Wiklund, A., Stenlund, T., Steinholtz, K., \& Ahlgren, C. (2010). Take charge: Patients' experiences during participation in a rehabilitation programme for burnout. Journal of Rehabilitation Medicine, 42, 475-481. doi: $10.2340 / 16501977-0534$

Glise, K., Ahlborg Jr, G., \& Jonsdottir, I. H. (2012). Course of mental symptoms in patients with stress-related exhaustion: does sex or age make a difference? BMC Psychiatry, 12, 18. doi: 10.1186/1471-244X-12-18

Graneheim, U., Lindgren, B., \& Lundman, B. (2017). Methodological challenges in qualitative content analysis: A discussion paper. Nurse Education Today, 56, 29-34. doi: 10.1016/j.nedt.2017.06.002

Graneheim, U., \& Lundman, B. (2004). Qualitative content analysis in nursing research: concepts, procedures and measures to achieve trustworthiness. Nurse Education Today, 24(2), 105-112. doi:10.1016/j.nedt.2003.10.001

Grossi, G., Perski, A., Osika, W., \& Savic, I. (2015). Stress-related exhaustion disorder - clinical manifestation of burnout? A review of assessment methods, sleep impairments, cognitive disturbances, and neuro-biological and physiological changes in clinical burnout. Scandinavian Journal of Psychology, 56, 626-636. doi: 10.1111/sjop.12251

Hsieh, H., \& Shannon, S. (2005). Three approaches to qualitative content analysis. Qualitative Health Research, 15(9), 1277-1288. doi: $10.1177 / 1049732305276687$

Jonsdottir, I., Nordlund, A., Ellbin, S., Ljung, T., Glise, K., Wahrborg, P., \& Wallin, A. (2013). Cognitive impairment in patients with stress-related exhaustion. Stress, 16(2), 181-190. doi:10.3109/10253890.2012.708950

Jonsdottir, I., Nordlund, A., Ellbin, S., Ljung, T., Glise, K., Währborg, P. et al. (2017). Working memory and attention are still impaired after three years in patients with stress-related exhaustion. Scandinavian Journal of Psychology, 58, 504-509. doi: 10.1111/sjop.12394

Kohn, M., \& Schooler, C. (1983). Work and personality: An inquiry into the impact of social stratification. Norwood: NJ, Ablex.

Krabbe, D., Ellbin, S., Nilsson, M., Jonsdottir, I. H., \& Samuelsson, H. (2017). Executive function and attention in patients with stress-related exhaustion: perceived fatigue and effect of distraction. Stress, 20, 333-340. doi: $10.1080 / 10253890.2017 .1336533$

This article is protected by copyright. All rights reserved 
620 Lincoln, Y., \& Guba, E. (1985). Naturalistic Inquiry. London.

621 Malmberg Gavelin, H., Boraxbekk, C.J., Stenlund, T., Slunga Järvholm, L., \& Stigsdotter Neely, A. (2015). Effects of a process-based cognitive training intervention for patients with stress-related exhaustion. Stress, 18(5), 578588. doi: 10.3109/10253890.2015.1064892

Malmberg Gavelin, H., Eskilsson, T., Boraxbekk, C. J, Josefsson, M., Stigsdotter Neely, A., \& Slunga Järvholm, L. (2018). Rehabilitation for improved

Malmberg Gavelin, H., Stigsdotter Neely, A., Andersson, M., Eskilsson, T., Slunga Järvholm, L., \& Boraxbekk, C. (2017). Neural activation in stress-related cognition in patients with stress-related exhaustion disorder: RECO - a

(1) randomized clinical trial. Stress, 21, 279-291. doi:

Oosterholt, B., Maes, J., Van der Linden, D., Verbraak, M., \& Kompier, M. (2014). 17(5), 400-409. doi:10.3109/10253890.2014.949668

Oosterholt, B., Maes, J., Van der Linden, D., Verbraak, M., \& Kompier, M. (2016).

Getting better, but not well: A 1.5 year follow-up of cognitive performance

National Board of Health and Welfare (2003). Utmattningssyndrom. Stressrelaterad Stockholm: National Board of Health and Welfare. [In Swedish].

\footnotetext{
Cognitive performance in both clinical and non-clinical burnout. Stress,
} and cortisol levels in clinical and non-clinical burnout. Biological Psychology, 117, 89-99. doi: 10.1016/j.biopsycho.2016.02.009

Ryan, R., \& Deci, E. (2000). Self-determination theory and the facilitation of intrinsic motivation, social development, and well-being. American Psychologist, 55, 68-78. doi: 10.1037110003-066X.55.1.68

Stenlund, T., Nordin, M., \& Slunga Järvholm, L. (2012). Effects of rehabilitation 651 programmes for patients on long-term sick leave for burnout: a 3-year followup of the REST-study. Journal of Rehabilitation Medicine, 44, 684-690. doi: $10.2340 / 16501977-1003$ 
652 Swedish Social Insurance Agency. (2017). Psykiatriska diagnoser. Korta analyser 2017:1. [Psychiatric diagnoses. Short analyses 2017:1] Stockholm: Försäkringskassan. [In Swedish].

655 Teixeira, P., Carraça, E., Markland, D., Silva, M., \& Ryan, R. (2012). Exercise,

656 physical activity, and self-determination theory: A systematic review. International Journal of Behavioral Nutrition and Physical Activity 9 (78).

659 Wallensten, J., Asberg, M., Wiklander, M., \& Nager, A. (2019). Role of

660 rehabilitation in chronic stress induced exhaustion disorder: a narrative

661 review. Journal of Rehabilitation Medicine, 51, 331-342. doi:10.2340/16501977-2545

663 van Dam, A., Keijsers, G., Eling, P., \& Beckers, E. (2011). Testing whether reduced 664 cognitive performance in burnout can be reversed by a motivational 665 intervention. Work \& Stress, 25(3), 257-271.

666 doi:10.1080/02678373.2011.613648

667 Öhman, L., Nordin, S., Bergdahl, J., Slunga Birgander, L., \& Stigsdotter Neely, A. 668 (2007). Cognitive function in outpatients with perceived chronic stress.

669 Scandinavian Journal of Work, Environment \& Health, 33, 223-232. doi:10.5271/sjweh.1131

671 Österberg, K., Skogsliden, S., \& Karlsson, B. (2014). Neuropsychological sequelae 672 of work-stress-related exhaustion. Stress, 17, 59-69. doi: $673 \quad 10.3109 / 10253890.2013 .862615$
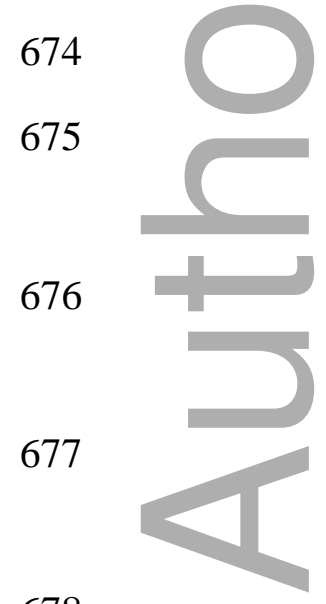
680

681

682
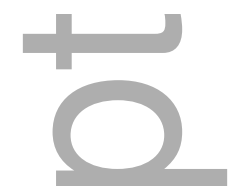

683

$\square$

684

685
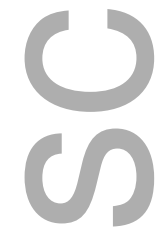

686

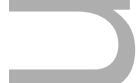

687 FIGURE LEGENDS

688 Figure 1. Study design and description of the 12-week intervention of computerized 689 cognitive training and aerobic training.

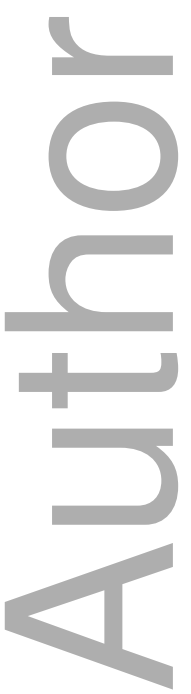

This article is protected by copyright. All rights reserved 


\begin{tabular}{|l|l|l|l|}
\hline Theme & Hopeful struggling for health \\
\hline Categories & Support & Motivation & Sensations \\
\hline Sub-categories & Assistance from others & Balance and timing & Memory \\
& Technological support & Feedback & Strength \\
& Planning and routine & Pleasure & Faith \\
\hline
\end{tabular}
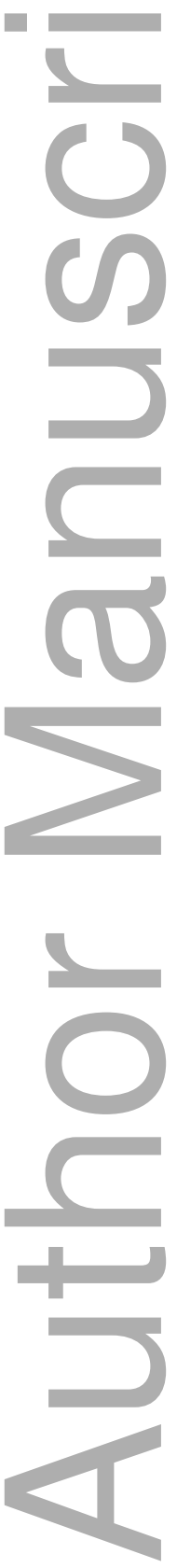


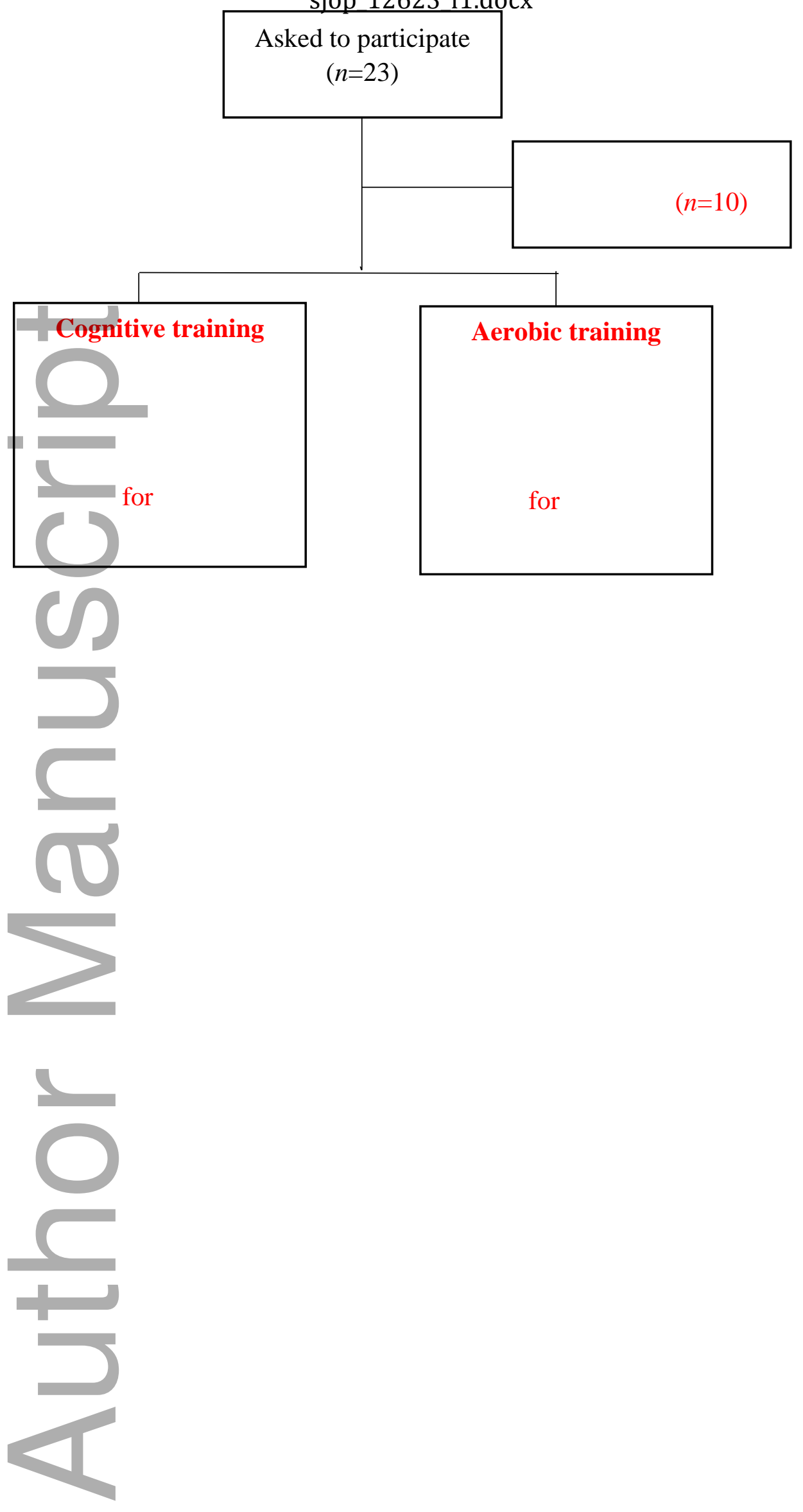

This article is protected by copyright. All rights reserved 


\section{University Library}

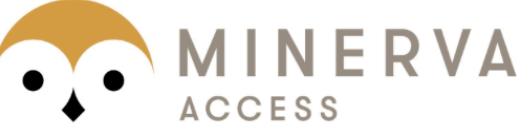

A gateway to Melbourne's research publications

Minerva Access is the Institutional Repository of The University of Melbourne

\section{Author/s:}

Eskilsson, T;Fjellman-Wiklund, A;Ek Malmer, E;Stigsdotter Neely, A;Malmberg Gavelin, $\mathrm{H}$;Slunga Jarvholm, L;Boraxbekk, C-J;Nordin, M

Title:

Hopeful struggling for health: Experiences of participating in computerized cognitive training and aerobic training for persons with stress-related exhaustion disorder

Date:

2020-01-29

Citation:

Eskilsson, T., Fjellman-Wiklund, A., Ek Malmer, E., Stigsdotter Neely, A., Malmberg Gavelin, H., Slunga Jarvholm, L., Boraxbekk, C. -J. \& Nordin, M. (2020). Hopeful struggling for health: Experiences of participating in computerized cognitive training and aerobic training for persons with stress-related exhaustion disorder. SCANDINAVIAN JOURNAL OF PSYCHOLOGY, 61 (3), pp.361-368. https://doi.org/10.1111/sjop.12623.

Persistent Link:

http://hdl.handle.net/11343/276836 